Article

\title{
Nickel Complexes Immobilized in Modified Ionic Liquids Anchored in Structured Materials for Ethylene Oligomerization
}

\author{
Camila A. Busatta ${ }^{1}$, Marcelo L. Mignoni ${ }^{2}$, Roberto F. de Souza ${ }^{3, \dagger}$ and Katia Bernardo-Gusmão ${ }^{3, *}$ \\ 1 Departmento de Ciências Exatas e da Terra, Universidade Regional Integrada do Alto Uruguai e das \\ Missões-URI, Av. Assis Brasil, 790, Itapagé, Frederico Westphalen 98400-000, Brazil; \\ camilapaguilar@yahoo.com.br \\ 2 Departmento de Química, Universidade Regional Integrada do Alto Uruguai e das Missões-URI, Av. Sete de \\ Setembro, 1621, Erechim 99700-000, Brazil; mignoni@uricer.edu.br \\ 3 LRC, Instituto de Química, Universidade Federal do Rio Grande do Sul-UFRGS, Av. Bento Gonçalves, 9500, \\ P.O. BOX 15003, Porto Alegre 91501-970, Brazil; rfds@iq.ufrgs.br \\ * Correspondence: katiabg@iq.ufrgs.br; Tel.: +55-51-3308-6481 \\ $\dagger$ In memoriam.
}

Received: 21 March 2018; Accepted: 24 April 2018; Published: 4 May 2018

Featured Application: Immobilized complexes in porous materials ( $\beta$-zeolite, MCM-41 and Al-MCM-41) modified with silylated ionic liquid were prepared and the catalytic systems were tested for ethylene oligomerization under homogeneous and heterogeneous conditions using toluene and EASC.

Abstract: This work describes the study of ethylene oligomerization reactions catalyzed by nickel- $\beta$-diimine complexes immobilized on $\beta$-zeolite, [Si]-MCM-41 (Mobil Composition of Matter 41 ) and [Si,Al]-MCM-41 modified with an ionic liquid. XRD and $\mathrm{N}_{2}$ adsorption and desorption analyses were used to characterize the modified supports-namely, IL-Zeo $\beta$, IL-MCM-41 and IL-Al-MCM-41-and the data showed that material organization remained intact even after incorporation of ionic liquid. $\mathrm{N}_{2}$ adsorption and desorption analyses suggested that ionic liquid can be confined in pores of support materials. Catalytic properties of synthesized materials were tested under different conditions. The following parameters were varied: $\mathrm{Al} / \mathrm{Ni}$ molar ratio, temperature, pressure and catalyst loading. The homogeneous catalysts were more active but less selective in ethylene oligomerization, relative to heterogeneous ones, which can be attributed to the effect of confinement suffered by catalyst within channels of the support materials. NiIL-Zeo $\beta$ complexes were active, with activities greater than $23 \mathrm{~s}^{-1}$ and selectivities higher than $80 \%$ for butenes, including more than $85 \%$ of 1-butene. On the other hand, the NiIL-MCM-41 system was less active than NiIL-Zeo $\beta$ complexes, with activities above $1 \mathrm{~s}^{-1}$ with $100 \%$ selectivity for butenes (96\% in 1-butene). NilL-Al-MCM-41 system was more active than NiIL-MCM-41 system and showed an activity of $2.3 \mathrm{~s}^{-1}$ with $90 \%$ selectivity in 1-butenes.

Keywords: ionic liquid; $\beta$-diimine; nickel; heterogenized; $\beta$-zeolite; MCM-41; oligomerization

\section{Introduction}

The oligomerization of ethylene is an important industrial reaction, and megatons of $\alpha$-olefins are produced in this way every year. Depending on the chain length of the alkene, these materials are used for manufacturing various products, ranging from plastics to lubricants and linear low-density polyethylene (LLDPE). Among the industrial processes used for ethylene oligomerization using 
homogeneous catalysis, many processes were developed by companies such as Shell (Shell High Olefins Process (SHOP)) [1] and the IFP-Institut Français du Pétrole (Dimersol and Alfabutol) [2,3]. These systems allow the production of products with high activities and selectivities; however, the separation of the products from the reaction medium makes catalyst recycling a challenge. The use of heterogeneous catalytic systems may be an interesting way to address the issue of separating the catalyst from the reaction products, increase the catalysts' resistance and facilitate its reuse [4].

Currently, a wide variety of molecular sieves are available, including zeolites, and these materials have become important as catalysts and adsorbents [5-7]. Molecular sieves are most commonly used in processes that employ relatively small molecules due to the sizes of their pores, which are approximately $8 \AA$ [8]. The $\beta$-zeolite described by Mobil Oil Corporation is an example of a zeolite structure that is applicable in such a situation. The zeolite is a $\beta$-zeolite, which has a three-dimensional system of channels and micropores (diameters of $7.5 \AA$ ) that are circumscribed by rings of 12 tetrahedra that can be directly synthesized with a considerably high $\mathrm{Si} / \mathrm{Al}$ ratio. Its high acidity, thermal stability, and hydrothermal stability and the ease by which relatively large molecules can diffuse through the channels make this a very interesting material from the perspective of developing new catalytic zeolites.

Other supports used with the same propose are the mesoporous MCM-41 (Mobil Composition of Matter 41) solids. These supports represent a new platform because their morphological characteristics and pore diameters of between 2 and $50 \mathrm{~nm}$ allow the introduction of compounds with greater steric hindrance into the cavities. The solids [Si]-MCM-41 and [Si,Al]-MCM-41 [9] have high thermal stability and a hexagonal arrangement of pores with linear and parallel channels and are constructed with a beehive-type silica matrix. Use of MCM-41 as support of several metal complexes that are catalysts of ethylene, propylene or 1-hexene oligomerization reactions was described in the literature [6,10-14]. In all cases, the reported oligomer selectivity was affected by the presence of MCM- 41 .

We have used ionic liquids as solvents in several types of catalytic reactions (biphasic catalysis) $[15,16]$. Recently, a new type of tether was described in the literature in which the complex is anchored to the ionic liquid that is supported on mesoporous silica; this technique has been employed in hydroformylation [17-19], carbonylation [20], hydrogenation [21], Heck [22] and epoxidation [23] reactions.

In this work, a nickel- $\beta$-diimine complex was immobilized on $\beta$-zeolite, [Si]-MCM-41 and [Si,Al]-MCM-41 modified with the tetrafluoroborate of 1-(3-trimetoxisililpropil)-3-methylimidazolium ionic liquid in the presence of the tetrafluoroborate of 1-butyl-3-methylimidazolium (BMI.BF4). The catalyst obtained was used in ethylene oligomerization reactions.

\section{Materials and Methods}

All syntheses were performed under an argon atmosphere using standard Schlenk techniques. Ethylene (White Martins 99.99\%) was used for the catalytic tests. The cocatalyst ethylaluminum sesquichloride (EASC) was used after being diluted in toluene $(10 \% v / v)$. Characterization of the compounds was done using gas chromatography (GC), nuclear magnetic resonance (NMR), elemental analysis, $\mathrm{N}_{2}$ adsorption, infrared (IR) spectroscopy, $\mathrm{X}$-ray diffraction (XRD), and atomic absorption spectroscopy (AAS), as detailed in the following. GC was performed in a Varian Star 3400 CX chromatograph with a flame ionization detector, equipped with a Petrocol DH capillary column (methyl silicone, $100 \mathrm{~m}$ in length, $0.25 \mathrm{~mm}$ ID, $0.5 \mu \mathrm{m}$ film thickness). The temperature was initially maintained at $36{ }^{\circ} \mathrm{C}$ for $15 \mathrm{~min}$, followed by heating to $250{ }^{\circ} \mathrm{C}$ at a rate of $5^{\circ} \mathrm{C} / \mathrm{min}$. ${ }^{1} \mathrm{H}$ - and ${ }^{13} \mathrm{C}-\mathrm{NMR}$ spectroscopy employed a Varian $300 \mathrm{NMR}$ spectrometer, operating at $300 \mathrm{MHz}$ for ${ }^{1} \mathrm{H}-\mathrm{NMR}$ and $75 \mathrm{MHz}$ for ${ }^{13} \mathrm{C}-\mathrm{NMR}$, using $\mathrm{CDCl}_{3}$ as solvent. Elemental analysis used a Perkin Elmer M CHN/O Model 2400 system. $\mathrm{N}_{2}$ adsorption utilized a Quantachrome Nova 2200e model system in conjunction with the BET method to determine the specific surface area of samples previously treated at $80^{\circ} \mathrm{C}$ by $3 \mathrm{~h}$. Vibrational spectroscopy used a Shimadzu infrared spectrometer. XRD was performed using a diffractometer from Siemens (model D500) with CuK $\alpha$ radiation $(\lambda=1.54 \AA$ ). For AAS, done in a spectrometer from Perkin Elmer (A. Analyst 200), $20 \mathrm{mg}$ of samples were prepared with $2 \mathrm{~mL}$ of $\mathrm{HCl}$, 
$6 \mathrm{~mL}$ of $\mathrm{HNO}_{3}, 5 \mathrm{~mL}$ of $\mathrm{HF}$, adding the mixture to Teflon autoclaves, subsequently using a digester for $10 \mathrm{~h}$ at $150^{\circ} \mathrm{C}$. After cooling, the samples were diluted to $50 \mathrm{~mL}$.

\subsection{Ligand 2-(phenyl)amino-4-(phenyl)imino-2-pentene}

An argon-filled glass flask was charged with $30 \mathrm{~mL}$ of toluene, $10 \mathrm{~mL}$ of acetylacetone (100 mmol) and $18 \mathrm{~mL}$ of aniline $(200 \mathrm{mmol})$. This mixture was cooled in an ice bath and then $8.3 \mathrm{~mL}$ of concentrated hydrochloric acid was slowly added to the flask. After $24 \mathrm{~h}$, a precipitate was obtained that was then isolated by filtration and washed with hexane. The solid was neutralized and extracted by adding $8 \mathrm{~mL}$ of dichloromethane, $50 \mathrm{~mL}$ of distilled water and $20 \mathrm{~mL}$ of saturated solution of sodium carbonate. Next, a pear-shaped separation flask was used to extract the organic phase. The solution was concentrated under reduced pressure, and the ligand was crystalized from methanol and left in the freezer. We obtained $9.13 \mathrm{~g}$ of the ligand ( $36.5 \mathrm{mmol}, 36.5 \%$ yield) as a yellow solid. The ligand was characterized by ${ }^{1} \mathrm{H}-\mathrm{NMR}$ spectroscopy $\left(\mathrm{CDCl}_{3}, 300 \mathrm{MHz}\right.$, Room temperature, $\delta$ in ppm): $12.7\left(\mathrm{~s}, 1 \mathrm{H}, \mathrm{H}_{9}\right), 7.3-6.9\left(\mathrm{~m}, 10 \mathrm{H}, \mathrm{H}_{4}, \mathrm{H}_{5}, \mathrm{H}_{6}, \mathrm{H}_{7}, \mathrm{H}_{8}\right), 4.9\left(\mathrm{~s}, 1 \mathrm{H}, \mathrm{H}_{2}\right), 2\left(6 \mathrm{H}, \mathrm{H}_{1}, \mathrm{H}_{3}\right)$. Anal. Calc for $\mathrm{C}_{17} \mathrm{H}_{18} \mathrm{~N}_{2}$ : C, 81.56; H, 7.25; N, 11.19. Found: $\mathrm{C}, 81.24 ; \mathrm{H}, 7.41 ; \mathrm{N}, 11.35$.

\subsection{Synthesis of the Bis-(acetonitrile)dibromidonickel(II) Adduct [24]}

To a $250 \mathrm{~mL}$ Schlenk tube, $120 \mathrm{~mL}$ of acetonitrile and $2.26 \mathrm{~g}$ of $\mathrm{NiBr}_{2}$ (anhydrous) were added. This suspension remained under reflux at $80{ }^{\circ} \mathrm{C}$ until a dark blue color was obtained. The final solution was concentrated to approximately $40 \mathrm{~mL}$ under reduced pressure, and the resulting solid was filtered through a fritted filter Schlenk tube, washed with $30 \mathrm{~mL}$ of acetonitrile and then dried under flowing argon.

\subsection{Synthesis of the 1,5-Bisphenyl-2,4-pentanediimine-dibromidonickel(II) Complex}

The complex was synthesized as described in the literature [25]. To a $250 \mathrm{~mL}$ Schlenk tube, the diimine ligand $(0.77 \mathrm{~g}, 3.08 \mathrm{mmol}$ ) (which was synthesized as described in Section 3.1) and $40 \mathrm{~mL}$ of dichloromethane were added. To this solution, the bis-(acetonitrile)dibromidonickel(II) adduct (0.914 $\mathrm{g}$, $3.04 \mathrm{mmol}$ ) was added. The reaction mixture was magnetically stirred for 4 days at room temperature. After the reaction was complete, the solution was concentrated to approximately $15 \mathrm{~mL}$ and filtered through a fritted filter Schlenk tube before the solvent was evaporated under vacuum to obtain the resulting solid nickel complex (light purple). We isolated $0.48 \mathrm{~g}$ of the complex (33\% yield). Anal. Calc for $\mathrm{C}_{19} \mathrm{H}_{24} \mathrm{Br}_{2} \mathrm{~N}_{2} \mathrm{Ni}$ : C, 45.74; H, 4.85; N, 5.61 Found: C, 44.76; H, 4.12; N, 6.01.

\subsection{Synthesis of 1-(3-Trimethoxysilylpropyl)-3-methylimidazolium Chloride}

The procedure used for the preparation of the ionic liquid was similar to the methods described in the literature [26]. 1-Methylimidazole ( $3.36 \mathrm{~g}, 40 \mathrm{mmol})$ and $7.92 \mathrm{~g}$ of 3-chloropropyltrimethoxysilane ( $40 \mathrm{mmol}$ ) were added to a Schlenk tube under argon. The reaction mixture was stirred for $24 \mathrm{~h}$ at $95^{\circ} \mathrm{C}$. A viscous oil formed after heating. This oil was used immediately in the next step. The assignments of the ${ }^{1} \mathrm{H}-\mathrm{NMR}$ and ${ }^{13} \mathrm{C}$-NMR signals of 1-(3-trimetoxisililpropil)-3-methylimidazoliumchloride are as follows: ${ }^{1} \mathrm{H}-\mathrm{NMR}\left(\mathrm{CDCl}_{3}\right): \delta(\mathrm{ppm})=0.65(\mathrm{t}, 2 \mathrm{H}), 2.0(\mathrm{~m}, 2 \mathrm{H}), 3.6(\mathrm{~s}, 9 \mathrm{H}), 4.1(\mathrm{~s}, 3 \mathrm{H}), 4.36(\mathrm{t}, 2 \mathrm{H})$, $7.54(\mathrm{~s}, 1 \mathrm{H}), 7.83(\mathrm{~s}, 1 \mathrm{H}), 10.5(\mathrm{~s}, 1 \mathrm{H}) ;{ }^{13} \mathrm{C}-\mathrm{NMR}\left(\mathrm{CDCl}_{3}\right): \delta(\mathrm{ppm})=5.5\left(\mathrm{SiCH}_{2}\right), 24.0\left(\mathrm{CH}_{2}\right), 36.4\left(\mathrm{CH}_{3} \mathrm{~N}\right)$, $51.2\left(\mathrm{OCH}_{3}\right), 76.9\left(\mathrm{CH}_{2} \mathrm{~N}\right), 121.7,123.4,137.2$.

\subsection{Synthesis of 1-(3-Trimethoxysilylpropyl)-3-methylimidazoliumhexafluoro-phosphate}

To a solution of the above compound $(3.2 \mathrm{~g}, 10 \mathrm{mmol})$ in $15 \mathrm{~mL}$ of acetone, sodium tetrafluoroborate $(1.15 \mathrm{~g}, 10.5 \mathrm{mmol})$ was added. This mixture was stirred at room temperature for 3 days. The solid was then removed by filtration, and the solvent was evaporated. The assignments of the ${ }^{1} \mathrm{H}-\mathrm{NMR}$ and ${ }^{13} \mathrm{C}-\mathrm{NMR}$ signals of the tetrafluoroborate 1-(3-trimetoxisililpropil)-3-methylimidazolium are as follows: ${ }^{1} \mathrm{H}-\mathrm{NMR}\left(\mathrm{CDCl}_{3}\right), \delta(\mathrm{ppm})=0.65(\mathrm{t}, 2 \mathrm{H}), 2.0(\mathrm{~m}, 2 \mathrm{H}), 3.6(\mathrm{~s}, 9 \mathrm{H}), 3.9(\mathrm{~s}, 3 \mathrm{H}), 4.2(\mathrm{t}, 2 \mathrm{H}), 7.34(\mathrm{~s}, 1 \mathrm{H})$, 
$7.39(\mathrm{~s}, 1 \mathrm{H}), 8.90(\mathrm{~s}, 1 \mathrm{H}) ;{ }^{13} \mathrm{C}-\mathrm{NMR}\left(\mathrm{CDCl}_{3}\right), \delta(\mathrm{ppm})=6.1\left(\mathrm{SiCH}_{2}\right), 24.3\left(\mathrm{CH}_{2}\right), 36.7\left(\mathrm{CH}_{3} \mathrm{~N}\right), 51.7\left(\mathrm{CH}_{3} \mathrm{O}\right)$, $52.1\left(\mathrm{CH}_{2} \mathrm{~N}\right), 122.0,124.2,137.1$.

\subsection{Synthesis of the Supports}

$\beta$-Zeolite, with a ratio $\mathrm{Si} / \mathrm{Al}=20$, was synthesized as describe in the literature [27]. Before use, the $\beta$-zeolite was calcined at $600{ }^{\circ} \mathrm{C}$ for $6 \mathrm{~h}$ at a heating rate of $3{ }^{\circ} \mathrm{C} / \mathrm{min}$ to remove the ionic liquid, which had been used as a structure-directing agent and was present in the cavities.

The mesoporous supports, [Si]-MCM-41 and [Si,Al]-MCM-41, were synthesized according to the route proposed by Corma [28]. Finally, the obtained samples were calcined in air under static conditions at $540{ }^{\circ} \mathrm{C}$ for $6 \mathrm{~h}$ at a heating rate of $0.5^{\circ} \mathrm{C} / \mathrm{min}$, with $60 \mathrm{~min}$ holds at 150 and $350{ }^{\circ} \mathrm{C}$.

\subsection{Synthesis of Silylated Ionic Liquid-Modified Supports}

Ionic liquid (6.5 mmol) (synthesized as described in Section 2.4) was dissolved in chloroform $(50 \mathrm{~mL})$ and mixed with $1 \mathrm{~g}$ of support (previously dried under vacuum and heated to $180^{\circ} \mathrm{C}$ overnight). The mixture was heated to $65^{\circ} \mathrm{C}$ under reflux and stirred for $26 \mathrm{~h}$. The mixture was cooled to room temperature and filtered, and the solid was washed with chloroform $(50 \mathrm{~mL})$ and diethyl ether $(50 \mathrm{~mL})$. Afterwards, the solid was dried under reduced pressure.

The synthesized materials were named IL-Zeo $\beta$, IL-MCM-41 and IL-Al-MCM-41. The incorporation of the silylated ionic liquid onto the materials is outlined in Figure 1.

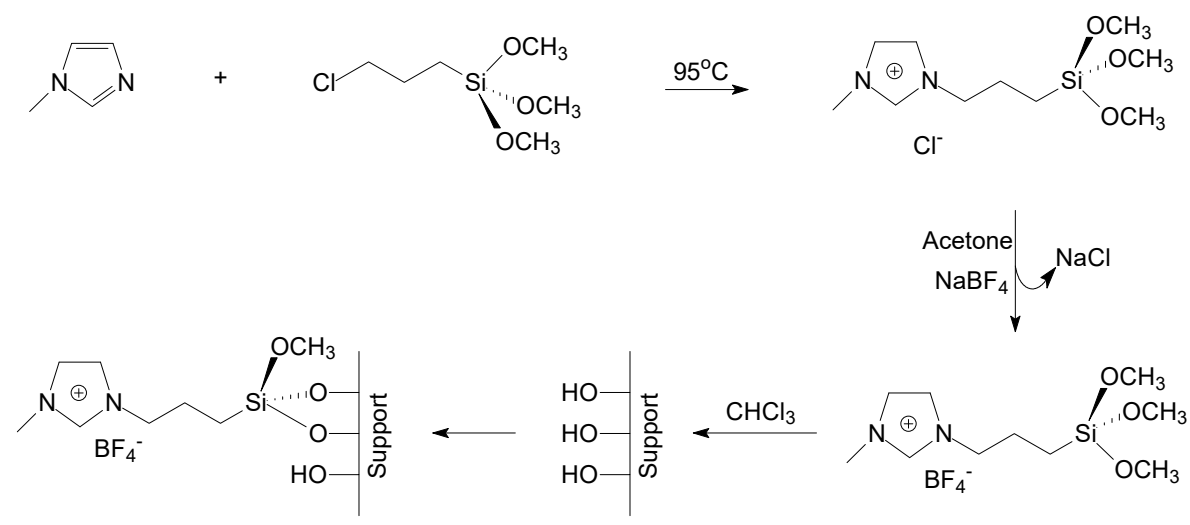

Figure 1. Scheme to synthesis of ionic liquid-modified supports.

\subsection{Immobilization of the Nickel- $\beta$-Diimine Complex onto the Modified Supports}

To a Schlenk tube, the nickel- $\beta$-diimine complex $(0.30 \mathrm{mmol})$ dissolved in $10 \mathrm{~mL}$ of

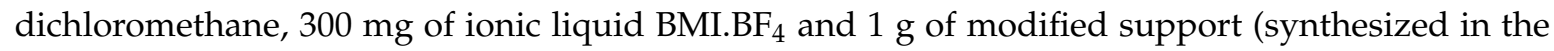
previous step) was added. The mixture was stirred for $1 \mathrm{~h}$ at room temperature and then the solvent was evaporated. The synthesized materials are named NiIL-Zeo $\beta$, NiIL-MCM-41 and NilL-Al-MCM-41.

\subsection{Catalytic Tests}

Ethylene oligomerization reactions were performed in triplicate, under both homogeneous and heterogeneous conditions, and the results were compared. The catalytic reactions were performed in a $200 \mathrm{~mL}$ double-walled glass reactor, equipped with a magnetic stirrer, a thermocouple, and a continuous feed of ethylene. The reaction temperature was controlled by a thermostatic circulation bath. All reactions employed $30 \mathrm{~mL}$ of toluene as the solvent and a solution of EASC as the cocatalyst. The amounts of catalyst and cocatalyst, as well as temperature and pressure, were optimized. After each reaction, the reactor was cooled with a mixture of ethanol and liquid $\mathrm{N}_{2}$ (to reach temperatures up to $-40{ }^{\circ} \mathrm{C}$ ). After cooling, the reaction mixture was poured into a vial for later analysis, and eventual quantification by gas chromatography using isooctane as an internal standard. The catalytic tests 
evaluated activity (expressed by turnover frequency (TOF), $\mathrm{s}^{-1}$ ) and selectivity ( $\%$ of butenes and $\%$ of 1-butene in fraction $\mathrm{C}_{4}$ ) as shown in Table 1.

Table 1. Expressions used for calculations of activity and selectivity of the oligomers.

\begin{tabular}{cc}
\hline Turnover Frequency (TOF) & mol of ethylene converted \\
\cline { 2 - 2 } Solectivity (\% butenes) & $\sum$ butenes mass \\
\hline Selectivity (\% 1-butene) & $\frac{1 \text {-butene mass }}{\sum \text { butenes mass }}$ \\
\hline Selectivity (\% internal butenes) & $\frac{\text { Internal butenes mass }}{\sum \text { butenes mass }}$ \\
\hline
\end{tabular}

Catalyst-recycling tests were performed with NiIL-Zeoß. After the first reaction, the products were removed from the reactor through a cannula and collected in a cooled Schlenk tube. Through this technique, we could isolate the NiIL-Zeo $\beta$ catalyst from the reactor while maintaining the argon atmosphere. Recycling was accomplished by adding another $30 \mathrm{~mL}$ of toluene and re-adding the same volume of EASC cocatalyst as in the first cycle.

\section{Results and Discussion}

First, we present the results of the characterization of the materials; next, we discuss the results of the catalytic oligomerization tests in detail.

\subsection{Materials Characterization}

In the infrared spectra of the supported complexes (Figure 2), there are specific bands at approximately 1098, 794 and $448 \mathrm{~cm}^{-1}$ that can be attributed to the vibrations of the mesoporous structure ( $\mathrm{Si}-\mathrm{O})$, a band at $547 \mathrm{~cm}^{-1}$ that can be assigned to the characteristic absorption of $\beta$-zeolite and mesoporous materials, and a broad band at approximately $3409 \mathrm{~cm}^{-1}$ that can be assigned to silanol groups (SiO-H). The bands at 3154 and $3098 \mathrm{~cm}^{-1}$ are assigned to the $\mathrm{CH}$ vibrations of the imidazole aromatic ring and the $\mathrm{CH}$ stretching of the alkyl groups belonging to the silylating agent. The bands at 2960 and $2870 \mathrm{~cm}^{-1}$ in the spectra of the supported complexes are assigned to symmetric and asymmetric stretches of the $\mathrm{CH}$ bonds present in the complexes, suggesting that the complexes were immobilized on the support.

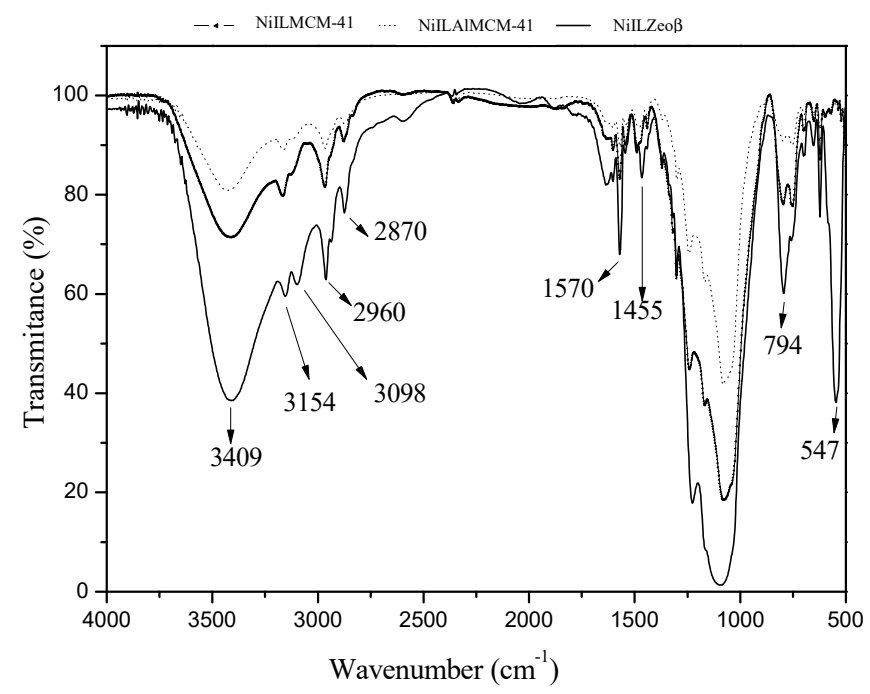

Figure 2. Infrared spectra of NiIL-Zeo $\beta$, NiIL-MCM-41 and NiIL-Al-MCM-41. 
Figure 3 shows the diffractograms that contain peaks characteristic of supports modified with an ionic liquid (IL-Zeo $\beta$, IL-MCMC-41 and IL-Al-MCM-41) as well as $\beta$-zeolite, MCM-41 and Al-MCMC-41 (upper right insets). Based on a comparison of the sets of spectra, we conclude that the network organization did not change, which confirms that the structure of these supports did not changed even after the immobilization of the silylated ionic liquid in their cavities. The spectra in Figure 3 are consistent with the XRD patterns reported in the literature [19].

a)

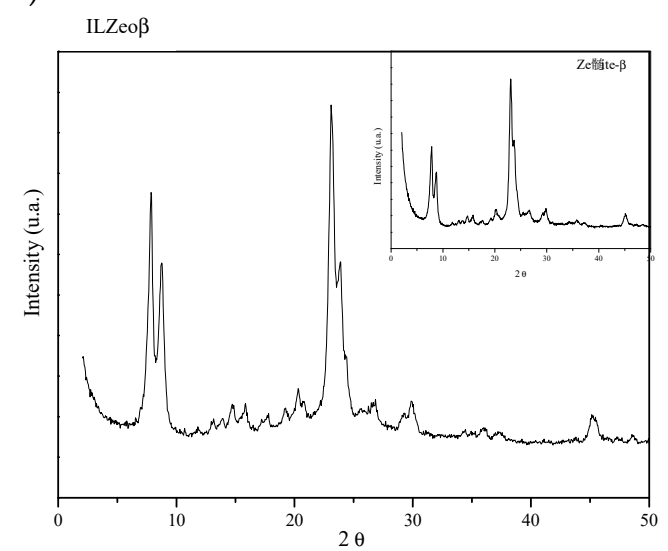

b)

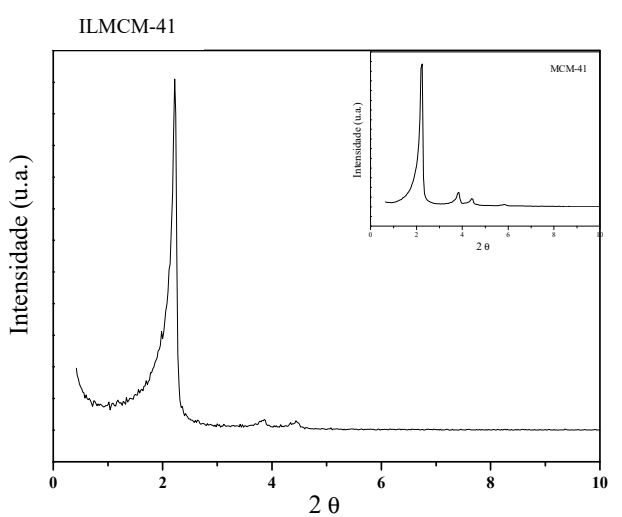

c)

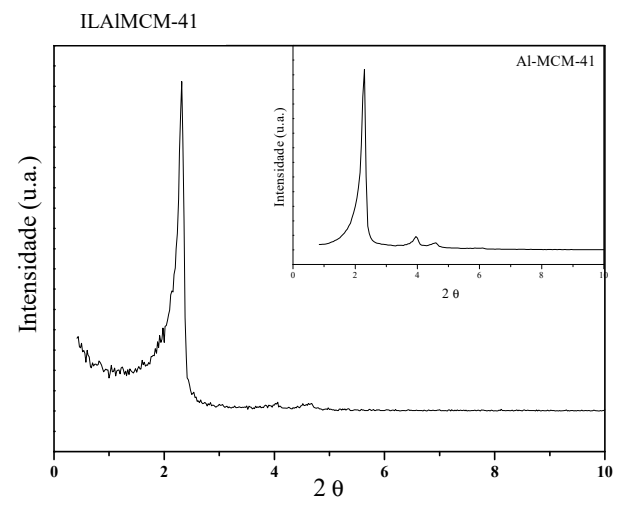

Figure 3. X-ray diffractograms of the (a) $\beta$-zeolite and IL-Zeo $\beta$; (b) MCM-41 (Mobil Composition of Matter 41) and IL-MCM-41; and (c) Al-MCM-41 and IL-Al-MCM-41.

Evaluation of specific regions of the spectra can be used to confirm the results obtained by XRD wherein the characteristics of the materials were maintained, even after incorporation of the ionic liquid. Analysis of these data showed significant reductions in the specific surface areas of the IL-Zeo $\beta$ from 418 to $32 \mathrm{~m}^{2} \mathrm{~g}^{-1}$, the IL-MCM-41 from 1038 to $403 \mathrm{~m}^{2} \mathrm{~g}^{-1}$ and the IL-Al-MCM-41 from 860 to $465 \mathrm{~m}^{2} \mathrm{~g}^{-1}$ due to the incorporation of a substantial number of organic groups. These results suggest that the ionic liquid can be immobilized in the pores of the materials.

Based on the elemental analysis, one can estimate the amount of ionic liquid that was anchored to each support. We obtained $8.92 \% \mathrm{C}, 1.39 \% \mathrm{H}$ and $2.29 \% \mathrm{~N}$ on the IL-Zeo $\beta$ support; $7.28 \% \mathrm{C}, 2.14 \% \mathrm{H}$ and $2.31 \% \mathrm{~N}$ on the IL-MCM-41 support; and $10.57 \% \mathrm{C}, 2.23 \% \mathrm{H}$ and $2.76 \% \mathrm{~N}$ on the IL-Al-MCM-41 support. From these results, one can calculate the amount of ionic liquid incorporated into each medium; the relevant results were $22.0 \%$ (indicating that $41 \%$ of ionic liquid added was immobilized on the Zeo $\beta$ support), $22.2 \%$ (indicating that $47 \%$ of ionic liquid added was immobilized on IL-MCM-41) and $27.5 \%$ (indicating that $61 \%$ of ionic liquid added was immobilized on IL-Al-MCM-41).

The results of texture analysis from $\mathrm{N}_{2}$ adsorption-desorption isotherms are shown in Table 2. 
The specific areas were calculated by the BET method, resulting in $1038 \mathrm{~m}^{2} \mathrm{~g}^{-1}$ for the MCM-41, $860 \mathrm{~m}^{2} \mathrm{~g}^{-1}$ for the Al-MCM-41 and $418 \mathrm{~m}^{2} \mathrm{~g}^{-1}$ for the $\beta$-zeolite, and 403, 465 and $32 \mathrm{~m}^{2} \mathrm{~g}^{-1}$ for IL-MCM-41, IL-Al-MCM-41 and IL- $\beta$-zeolite, respectively. As expected, a decrease in BET surface area is observed in the ionic liquid-modified materials.

Table 2. Structural properties of the synthesized materials.

\begin{tabular}{|c|c|c|}
\hline Support & $\mathrm{A}_{\mathrm{BET}}{ }^{\mathrm{a}}\left(\mathrm{m}^{2} \mathrm{~g}^{-1}\right)$ & Pore Diameter $^{b}(\AA ̊)$ \\
\hline MCM-41 & 1038 & 34 \\
\hline IL-MCM-41 & 403 & 28 \\
\hline Al-MCM-41 & 860 & 29 \\
\hline IL-Al-MCM-41 & 465 & 25 \\
\hline Zeo $\beta$ & 418 & - \\
\hline IL-Zeo $\beta$ & 32 & - \\
\hline
\end{tabular}

${ }^{\mathrm{a}} \mathrm{A}_{\mathrm{BET}}=$ specific area obtained using the BET method (total area). ${ }^{\mathrm{b}} \mathrm{Dp}=$ average pore diameter calculated by intervals obtained using the BJH desorption method.

To confirm the binding of the nickel complex to the $\beta$-zeolite, MCM-41 and Al-MCM-41, the heterogenized complexes were analyzed by flame atomic absorption. Analyses were done in triplicate, and the values are reported in Table 3. The amount of nickel incorporated per gram of support is $75 \pm 5 \%$ of added nickel, indicating the total immobilization of the complex. The NiIL-Zeo $\beta$ complex was also analyzed after an oligomerization reaction, and the results indicate that more than $50 \%$ of the immobilized complex in $\beta$-zeolite was lost during this reaction.

Table 3. The results from the atomic absorption spectroscopy (AAS) analysis of the $\beta$-diimine/ $\beta$-zeolite nickel complex.

\begin{tabular}{ccc}
\hline Support & (mmol Ni/g of Support) & (mmol Ni/g of Support) \\
\cline { 2 - 3 } & Added & by AAS \\
\hline NiIL-Zeo $\beta$ & & 0.21 \\
NiIL-MCM-41 & 0.3 & 0.23 \\
NiIL-Al-MCM-41 & & 0.24 \\
NiIL-Zeo $\beta$ & & $0.10^{\text {a }}$ \\
\hline
\end{tabular}

${ }^{\text {a }}$ Amount of nickel measured by AAS after a reaction run.

\subsection{Catalytic Tests Results}

\subsubsection{Homogeneous Catalytic Reactions}

Homogeneous reactions were conducted to assess the selectivity and activity of the nickel- $\beta$-diimine complex so that those parameters could be compared with those of the catalytic tests performed with the heterogenized catalyst probably due to decomposition.

Table 4 presents the results of the catalytic tests. The ratio of $\mathrm{Al} / \mathrm{Ni}$ was varied between 25 and 100 (entries 1-4). The highest activity was achieved at an $\mathrm{Al} / \mathrm{Ni}$ ratio of 50, and the highest selectivity in butenes at an $\mathrm{Al} / \mathrm{Ni}$ ratio of 25 . The increase in activity with the $\mathrm{Al} / \mathrm{Ni}$ ratio may be explained by an increase in the number of active species in the reaction medium. The maximum reactivity occurs before a decrease in activity, indicating catalyst deactivation, probably due to decomposition. 
Table 4. Activity and selectivity in homogeneous catalytic reactions.

\begin{tabular}{|c|c|c|c|c|c|c|c|c|}
\hline \multirow{2}{*}{ Entry } & \multirow{2}{*}{ Catalyst ( $\mu \mathrm{mol})$} & \multirow{2}{*}{$\mathrm{Al} / \mathrm{Ni}$} & \multirow{2}{*}{$\mathrm{T}\left({ }^{\circ} \mathrm{C}\right)$} & \multirow{2}{*}{ Pressure (atm) } & \multirow{2}{*}{ TOF $\left(s^{-1}\right)$} & \multicolumn{3}{|c|}{ Selectivity (\%) } \\
\hline & & & & & & $\mathrm{C}_{4}\left(1-\mathrm{C}_{4}\right)$ & $\mathrm{C}_{6}$ & $\mathrm{C}_{\geq 8}$ \\
\hline 1 & 5 & 25 & 10 & 5 & $4.7 \pm 0.1$ & $85(77)$ & 10 & 5 \\
\hline 2 & 5 & 50 & 10 & 5 & $19.3 \pm 0.2$ & $78(45)$ & 20 & 2 \\
\hline 3 & 5 & 75 & 10 & 5 & $15.9 \pm 0.2$ & $77(31)$ & 17 & 6 \\
\hline 4 & 5 & 100 & 10 & 5 & $14.4 \pm 0.2$ & $85(48)$ & 13 & 2 \\
\hline 5 & 5 & 100 & 23 & 5 & $73.1 \pm 0.2$ & $79(26)$ & 19 & 2 \\
\hline 6 & 10 & 50 & 10 & 5 & $15.7 \pm 0.2$ & $76(31)$ & 19 & 5 \\
\hline 7 & 5 & 50 & 10 & 10 & $18.0 \pm 0.2$ & $80(40)$ & 17 & 3 \\
\hline
\end{tabular}

Reaction conditions: solvent $=$ toluene, cocatalyst $=$ ethylaluminum sesquichloride (EASC).

When the amount of catalyst was changed from 5 to $10 \mu \mathrm{mol}$ (entries 2 and 6), the activity and selectivity of the system decreased. This may be interpreted as resulting from an increase in the number of moles of catalyst precursor, which promotes an increase in the amount of active species in the reaction. Thus, the relative amount of ethylene reacting with the catalytic species is reduced, resulting in lower activity and selectivity in butenes. The reduction was mainly observed in 1-butene selectivity, due to parallel isomerization reaction. $C_{6}$ production is not significantly affected, and $C_{8}$ products slightly increase. This is consistent with the results reported by Busico et al. [29].

By increasing the initial reaction temperature from 10 to $23^{\circ} \mathrm{C}$ (entries 4 and 5), the activity of the system also increases. Dubois et al. and Souza et al. [30,31] studied the influences of reaction temperature on oligomerization when using nickel complexes and found that the 1-butene best selectivity is achieved at low temperatures. Therefore, the subsequent reactions were performed at $10{ }^{\circ} \mathrm{C}$.

The last parameter to be studied was the pressure (entries 2 and 7). In the determination of the effects of pressure on the activity and selectivity in ethylene oligomerization, it can be observed that there are no meaningful changes in the selectivity of the system, likely because the system is close to ethylene saturation.

Comparing these results with the industrial Shell High Olefins Process (SHOP), our oligomerization process is more selective to light olefins $\left(C_{4}-C_{8}\right)$, while SHOP results in a larger range $\left(C_{4}-C_{40}\right)$.

\subsubsection{Catalytic Tests in Heterogeneous Reactions}

The catalytic properties of the $\beta$-zeolite-supported nickel- $\beta$-diimine complex were tested under different reaction conditions, as shown in Table 5. These experiments were performed to find the conditions under which the reaction showed the best activity and selectivity. We used the same amount of heterogenized catalyst precursor as was determined in the optimization of the homogeneous catalysis (i.e., $5 \mu \mathrm{mol}$ ).

The first parameter studied was the $\mathrm{Al} / \mathrm{Ni}$ molar ratio. Entries 8,9 and 10 present the results of catalytic tests with different molar ratios of aluminum from the cocatalyst and nickel. These results show that as we increase the $\mathrm{Al} / \mathrm{Ni}$ molar ratio, the activity of the catalyst also increases due to the increase in the concentration of active species present in the reaction mixture. 
Table 5. Results of catalytic tests of the complex supported on $\beta$-zeolite modified with ionic liquid.

\begin{tabular}{|c|c|c|c|c|c|c|c|}
\hline \multirow{2}{*}{ Entry } & \multirow{2}{*}{$\mathrm{Al} / \mathrm{Ni}$} & \multirow{2}{*}{$\mathrm{T}\left({ }^{\circ} \mathrm{C}\right)$} & \multirow{2}{*}{ Pressure (atm) } & \multirow{2}{*}{ TOF $\left(s^{-1}\right)$} & \multicolumn{3}{|c|}{ Selectivity (\%) } \\
\hline & & & & & $C_{4}\left(1-C_{4}\right)$ & $\mathrm{C}_{6}$ & $\mathrm{C}_{\geq 8}$ \\
\hline 8 & 25 & 10 & 5 & $1.1 \pm 0.1$ & $96(94)$ & 2 & 2 \\
\hline 9 & 50 & 10 & 5 & $3.3 \pm 0.2$ & $96(86)$ & 4 & - \\
\hline 10 & 100 & 10 & 5 & $3.8 \pm 0.1$ & $86(74)$ & 6 & 8 \\
\hline 11 & 100 & 23 & 5 & $23.5 \pm 1.0$ & $100(43)$ & - & - \\
\hline 12 & 50 & 10 & 2.5 & $3.0 \pm 0.2$ & $78(89)$ & 4 & 18.5 \\
\hline 13 & 50 & 10 & 10 & $9.1 \pm 0.2$ & $94(82)$ & 4 & 2 \\
\hline 14 & 50 & 10 & 5 & $5.0 \pm 0.1$ & $100(91)$ & - & - \\
\hline 15 & 50 & 10 & 5 & $0.12 \pm 0.01$ & $100(98)$ & - & - \\
\hline 16 & 50 & 10 & 5 & $0.06 \pm 0.01$ & $100(98)$ & - & - \\
\hline
\end{tabular}

After assessing the effect of the $\mathrm{Al} / \mathrm{Ni}$ molar ratio, we set out to determine the optimal temperature for the reaction to obtain the best activity and selectivity in the production of butenes. As shown in entry 10 , when the reaction was conducted at $10{ }^{\circ} \mathrm{C}$, the selectivity was approximately $74 \%$ for 1-butene. Based on entry 11 , when the reaction was performed at $23^{\circ} \mathrm{C}$, there was a decrease in the selectivity for 1-butene (approximately $43 \%$ ) compared to entry 10 . Using the conditions described above, this system shows higher selectivity than the homogeneous system (entries 4 and 5, Table 4), so the other reactions were performed at $10^{\circ} \mathrm{C}$.

The following studies were performed with pressures between 2.5, 5 and $10 \mathrm{~atm}$ to determine the effect of pressure on the activity of the oligomerization of ethylene. It can be observed from entries 9,12 and 13 that the role of pressure in the system is very important. When comparing the results of reactions run at 2.5 and $5 \mathrm{~atm}$, a slight difference in activity values can be observed, which can be explained by the difficulty of ethylene insertion into the cavities of zeolite due to the presence of the ionic liquid used as catalyst support. On the other hand, increasing the pressure from 5 to $10 \mathrm{~atm}$ increases the solubility of ethylene and, as a result, the ethylene enters the cavities, making it closer to the active species, which may explain the increased activity.

When comparing the homogeneous (entry 7, Table 4) and heterogeneous (entry 13, Table 5) reactions at $10 \mathrm{~atm}$, it was observed that the heterogeneous reaction was more selective than the homogeneous reaction for 1-butene, which shows that the catalyst lies within the cavities of the $\beta$-zeolite and that the increase in selectivity is due to the confinement effect of the catalyst. However, based on the selectivities observed in hexenes and octenes, the reaction may also be occurring with the homogeneous catalyst, as demonstrated by atomic absorption analysis after the reaction of the nickel complex immobilized on $\beta$-zeolite. Our results show higher activity in heterogeneous media than is reported in the literature [7].

The next step was to test the catalytic properties of the NiIL-MCM-41 (entries 17, 18 and 19, Table 6) and NilL-Al-MCM-41 (entry 20) catalysts under the best conditions obtained for the $\beta$-zeolite-supported $\beta$-diimine nickel complex: temperature $\left(10{ }^{\circ} \mathrm{C}\right)$, moles of catalyst $(5 \mu \mathrm{mol})$, pressure $(10 \mathrm{~atm})$ and reaction time $(30 \mathrm{~min})$. As shown in Table 5 , these catalysts are less active than the $\beta$-zeolite-supported system; however, these catalysts are $100 \%$ selective for butenes. When the $\mathrm{Al} / \mathrm{Ni}$ ratio was increased from 25 to 100, it was found that, at an $\mathrm{Al} / \mathrm{Ni}$ ratio of 50, the selectivity of the system did not vary significantly with respect to the activity; the catalytic system was more active, which indicates an increase in the active species present in the reaction medium. 
Table 6. Results of catalytic tests of the complex supported on MCM-41 and Al-MCM-41 modified with ionic liquid.

\begin{tabular}{cccccc}
\hline \multirow{2}{*}{ Entry } & \multirow{2}{*}{$\mathbf{A 1} / \mathbf{N i}$} & TOF $_{\left(\mathbf{s}^{-\mathbf{1}}\right)}$ & \multicolumn{3}{c}{ Selectivity (\%) } \\
\cline { 4 - 6 } & & & $\left.\mathbf{C}_{\mathbf{4}} \mathbf{( 1 - C}_{\mathbf{4}}\right)$ & $\mathbf{C}_{\mathbf{6}}$ & $\mathbf{C}_{\geq \mathbf{8}}$ \\
\hline 17 & 25 & $1.0 \pm 0.1$ & $100(94)$ & - & - \\
18 & 50 & $1.4 \pm 0.1$ & $100(96)$ & - & - \\
19 & 100 & $1.0 \pm 0.1$ & $100(93)$ & - & - \\
$20^{*}$ & 100 & $2.3 \pm 0.1$ & $100(90)$ & - & - \\
\hline
\end{tabular}

* NilLAl-MCM-41. Reactive conditions: solvent $=$ toluene, cocatalyst $=\mathrm{EASC}, \mathrm{n}_{\text {catalyst }}=5 \mu \mathrm{mol}$, temperature $=10^{\circ} \mathrm{C}$, pressure $=10 \mathrm{~atm}$.

In our analysis of the results of the catalytic test with NiIL-Al-MCM-41, we observed that the system was highly active (approximately $2.3 \mathrm{~s}^{-1}$ ) and reached $90 \%$ selectivity for 1-butene, which makes its activity superior to that of the NiIL-MCM-41 system.

Comparing the selectivities of the three heterogeneous and homogeneous systems, we observed that the effect of the confinement of the catalyst inside the MCM-41 pores was a determining factor in the high selectivity of the heterogeneous system, in this case. However, when comparing the supports used, we observed that the difference in the pore size of these materials was not a determining factor for the activity of the reactions, but rather the presence of acid sites in the structure of the $\beta$-zeolite and Al-MCM-41 was a determining factor. Hulea et al. [32] reported that the content of both nickel and acid sites contribute to the activation of the oligomerization reaction.

\section{Conclusions}

In this work, we described synthesis and caractherization of nickel- $\beta$-diimine complexes immobilized on $\beta$-zeolite, [Si]-MCM-41 and [Si,Al]-MCM-41 modified with an ionic liquid. These catalytic systems were used in ethylene oligomerization reactions and compared with the same reactions in homogeneous media. Catalytic properties of synthesized materials were tested under different conditions, varying $\mathrm{Al} / \mathrm{Ni}$ molar ratio, temperature, pressure and catalyst loading.

The results obtained in oligomerization reactions demonstrate the efficiency of heterogenized catalystic system. The techniques of characterization of the different complexes supported on $\beta$-zeolite or mesoporous materials of the MCM type corroborate that immobilization of the complex did not alter the structure of the supports of Si and Al.

Comparison between the heterogeneous systems indicates that differences in pore sizes of the support materials did not influence the activity, but the presence and strength of acid sites, occurring in $\beta$-zeolite and Al-MCM-41, affects reaction activity. We suggest that the effect of acid sites of the support on the metal site is to increase the strength of ethylene coordination to the metal, causing the system to be more active.

Comparison between homogeneous and heterogeneous systems containing the $\beta$-diimine-nickel complex showed that heterogenized systems are more selective in the formation of 1-butene. This higher selectivity indicates a positive relationship between porosity and confinement of the catalyst within channels of the support materials.

Author Contributions: Katia Bernardo-Gusmão and Roberto Fernando de Souza conceived and designed the experiments; Camila A. Busatta performed the experiments; Katia Bernardo-Gusmão, Camila Aguilar Busatta and Marcelo Luis Mignoni analyzed the data and wrote the paper.

Acknowledgments: The authors thank CNPq for their financial support in the form of grants.

Conflicts of Interest: The authors declare no conflict of interest. 


\section{References}

1. Freitas, E.R.; Gum, C.R. Shells higher olefins process. Chem. Eng. Prog. 1979, 25, 73-76.

2. Chauvin, Y.; Gaillard, J.F.; Quang, D.V.; Andrews, J.W. IFP Dimersol process for dimerization of C3 and C4 olefinic cuts. Chem. Ind. 1974, 375-378.

3. Commereuc, D.; Chauvin, Y.; Gaillard, J.F.; Léonard, J.; Andrews, J. Dimerize ethylene to butene-1. Hidrocarbon Process 1984, 63, 118-120.

4. Rossetto, E.; Nicola, B.P.; de Souza, R.F.; Pergher, S.B.C.; Bernardo-Gusmão, K. Anchoring via covalent binding of beta-diimine-nickel complexes in SBA-15 and its application in catalytic reactions. Appl. Catal. A 2015, 502, 221-229. [CrossRef]

5. Rossetto, E.; Caovilla, M.; Thiele, D.; de Souza, R.F.; Bernardo-Gusmão, K. Ethylene oligomerization using nickel-beta-diimine hybrid xerogels produced by the sol-gel process. Appl. Catal. A 2013, 454, 152-159. [CrossRef]

6. De Souza, M.O.; de Souza, R.F.; Rodrigues, L.R.; Pastore, H.O.; Gauvin, R.M.; Gallo, J.M.R.; Favero, C. Heterogenized nickel catalysts for propene dimerization: Support effects on activity and selectivity. Catal. Commun. 2013, 32, 32-35. [CrossRef]

7. Rossetto, E.; Nicola, B.P.; de Souza, R.F.; Bernardo-Gusmão, K.; Pergher, S.B.C. Heterogeneous complexes of nickel MCM-41 with beta-diimine ligands: Applications in olefin oligomerization. J. Catal. 2015, 323, $45-54$. [CrossRef]

8. Martins, L.; Cardoso, D. Catalytic applications of basic micro and mesoporous molecular sieves. Quím. Nova 2006, 29, 358-364. [CrossRef]

9. Beck, J.S.; Vartuli, J.C.; Roth, W.J. A new family of mesoporous molecular sieves prepared with liquid-cristal. J. Am. Chem. Soc. 1992, 114, 10834-10843. [CrossRef]

10. Guo, C.Y.; Xu, H.; Zhang, M.; Zhang, X.; Yan, F.; Yuan, G. Immobilization of bis(imino)pyridine iron complexes onto mesoporous molecular sieves and their catalytic performance in ethylene oligomerization. Catal. Commun. 2009, 10, 1467-1471. [CrossRef]

11. Van Looveren, L.K.; de Vos, D.E.; Vercruysse, K.A.; Geysen, D.F.; Janssen, B.; Jacobs, P.A. Oligomerization of propene on an alumoxane-grafted MCM-41 host with bis(cyclopentadienyl)zirconium dimethyl $\left(\mathrm{Cp}_{2} \mathrm{Zr}\left(\mathrm{CH}_{3}\right)_{2}\right)$. Catal. Lett. 1998, 56, 53-56. [CrossRef]

12. Shao, H.; Zhou, H.; Guo, X.; Tao, Y.; Jiang, T.; Qin, M. Chromium catalysts supported on mesoporous silica for ethylene tetramerization: Effect of the porous structure of the supports. Catal. Commun. 2015, 60, 14-18. [CrossRef]

13. De Souza, M.O.; Rodrigues, L.R.; Pastore, H.O.; Ruiz, J.A.C.; Gengembre, L.; Gauvin, R.M.; de Souza, R.F. A nano-organized ethylene oligomerization catalyst: Characterization and reactivity of the $\mathrm{Ni}(\mathrm{MeCN})_{6}\left(\mathrm{BF}_{4}\right)_{2} /[\mathrm{Al}]-\mathrm{MCM}-41 / \mathrm{AlEt}_{3}$ system. Microporous Mesoporous Mater. 2006, 96, 109-114. [CrossRef]

14. De Souza, M.O.; Rodrigues, L.R.; Gauvin, R.M.; de Souza, R.F.; Pastore, H.O.; Gengembre, L.; Ruiz, J.A.C.; Gallo, J.M.R.; Milanesi, T.S.; Milani, M.A. Support effect in ethylene oligomerization mediated by heterogenized nickel catalysts. Catal. Commun. 2010, 11, 597-600. [CrossRef]

15. Borba, K.M.N.; de Souza, M.O.; de Souza, R.F.; Bernardo-Gusmão, K. beta-Diimine nickel complexes in BMI center dot $\mathrm{AlCl}_{4}$ ionic liquid: A catalytic biphasic system for propylene oligomerization. Appl. Catal. A 2017, 538, 51-58. [CrossRef]

16. Thiele, D.; de Souza, R.F. Biphasic ethylene oligomerization using bis(imino)pyridine cobalt complexes in methyl-butylimidazolium organochloroaluminate ionic liquids. J. Mol. Catal. A 2011, 340, 83-88. [CrossRef]

17. Mehnert, C.P.; Cook, R.A.; Dispenziere, N.C.; Afeworki, M. Supported ionic liquid catalysis-A new concept for homogeneous hydroformylation catalysis. J. Am. Chem. Soc. 2002, 124, 12932-12933. [CrossRef] [PubMed]

18. Riisager, A.; Wasserscheid, P.; van Hal, R.; Fehrmann, R. Continuous fixed-bed gas-phase hydroformylation using supported ionic liquid-phase (SILP) Rh catalysts. J. Catal. 2003, 219, 452-455. [CrossRef]

19. Panda, A.G.; Bhor, M.D.; Jagtap, S.R.; Bhanage, B.M. Selective hydroformylation of unsaturated esters using a $\mathrm{Rh} / \mathrm{PPh}_{3}$-supported ionic liquid-phase catalyst, followed by a novel route to pyrazolin-5-ones. Appl. Catal. A 2008, 347, 142-147. [CrossRef]

20. Riisager, A.; Jørgensen, B.; Wasserscheid, P.; Fehrmann, R. First application of supported ionic liquid phase (SILP) catalysis for continuous methanol carbonylation. Chem. Commun. 2006, 994-996. [CrossRef] [PubMed] 
21. Mehnert, C.P.; Mozeleski, E.J.; Cook, R.A. Supported ionic liquid catalysis investigated for hydrogenation reactions. Chem. Commun. 2002, 3010-3011. [CrossRef]

22. Hagiwara, H.; Sugawara, Y.; Isobe, K.; Hoshi, T.; Suzuki, T. Immobilization of Pd(OAc) 2 in ionic liquid on silica: Application to sustainable Mizoroki-Heck reaction. Org. Lett. 2004, 6, 2325-2328. [CrossRef] [PubMed]

23. Yamaguchi, K.; Yoshida, C.; Uchida, S.; Mizuno, N. Peroxotungstate immobilized on ionic liquid-modified silica as a heterogeneous epoxidation catalyst with hydrogen peroxide. J. Am. Chem. Soc. 2005, 127, 530-531. [CrossRef] [PubMed]

24. Tang, L.; Duan, Y.; Li, X.; Li, Y. Syntheses, structure and ethylene polymerization behavior of beta-diiminato titanium complexes. J. Organomet. Chem. 2006, 691, 2023-2030. [CrossRef]

25. Feldman, J.; McLain, S.J.; Parthasarathy, A.; Marshall, W.J.; Calabrese, J.C.; Arthur, S.D. Electrophilic metal precursors and a beta-diimine ligand for nickel(II)- and palladium(II)-catalyzed ethylene polymerizations. Organometallics 1997, 16, 1514-1516. [CrossRef]

26. Sahoo, S.; Kumar, P.; Lefebvre, F.; Halligudi, S.B. Oxidative kinetic resolution of alcohols using chiral Mn-salen complex immobilized onto ionic liquid modified silica. Appl. Catal. A 2009, 354, 17-25. [CrossRef]

27. Mignoni, M.L.; de Souza, M.O.; Pergher, S.B.C.; de Souza, R.F.; Bernardo-Gusmão, K. Nickel oligomerization catalysts heterogenized on zeolites obtained using ionic liquids as templates. Appl. Catal. A 2010, 374, $26-30$. [CrossRef]

28. Corma, A.; Kan, Q.; Navarro, M.T.; Pariente, J.P.; Rey, F. Synthesis of MCM-41 with different pore diameters without addition of auxiliary organics. Chem. Mater. 1997, 9, 2123-2126. [CrossRef]

29. Busico, V.; Cipullo, R. Influence of monomer concentration on the stereospecificity of 1-alkene polymerization promoted by C-2-simmetrical ansa-metallocene catalysts. J. Am. Chem. Soc. 1994, 116, 9329-9330. [CrossRef]

30. Sauthier, M.; Leca, F.; de Souza, R.F.; Bernardo-Gusmão, K.; Queiroz, L.F.T.; Toupet, L.; Réau, R. $\mathrm{NiCl}_{2}$ (1,2-diiminophosphorane) complexes: A new family of readily accessible and tuneable catalysts for oligomerisation of ethylene. New J. Chem. 2002, 26, 630-635. [CrossRef]

31. De Souza, R.F.; Bernardo-Gusmão, K.; Cunha, G.A.; Loup, C.; Leca, F.; Réau, R. Ethylene dimerization into 1-butene using 2-pyridylphosphole nickel catalysts. J. Catal. 2004, 226, 235-239. [CrossRef]

32. Hulea, V.; Fajula, F. Ni-exchanged AlMCM-41-An efficient bifunctional catalyst for ethylene oligomerization. J. Catal. 2004, 225, 213-222. [CrossRef] 